\title{
Nutrient Transport and Mixing in the Gulf Stream
}

\author{
J. L. Pelegrí and G. T. Csanady \\ Old Dominion University, Norfolk, Virginia
}

\begin{abstract}
The distribution of nutrient flux (geostrophic velocity times concentration) in five sections across the Gulf Stream-North Atlantic Current (from the Florida Straits to $35^{\circ} \mathrm{W}$ ) is characterized by an intense core, centered at the depth of the $26.8 \sigma_{t}$ isopycnal surface (typically $500 \mathrm{~m}$ ). This "nutrient stream" carries nutrient transports of the order of $10^{3} \mathrm{kmol} \mathrm{s}^{-1}$ of nitrate and proportional amounts of other nutrients. Between the Florida Straits and the Mid-Atlantic Bight, water transport doubles, but nutrient transport trebles, because along-isopycnal inflow from the subtropical gyre is concentrated in the layers of the upper thermocline, which are rich in nutrients. Beyond the Mid-Atlantic Bight, both water and nutrient transports decline slowly. Water mass and nutrient balances of nine isopycnal layers reveal significant upward entrainment and mixing of thermocline waters in the sector of the stream between the Florida Straits and the Mid-Atlantic Bight. A two-box model of the nutrientdepleted surface layers $\left(\sigma_{t}<26.8\right)$ and the nutrient-rich thermocline layers $\left(26.8<\sigma_{t}<27.5\right)$ shows an upward entrainment rate of about $1.6 \mathrm{~m}^{2} \mathrm{~s}^{-1}$ per unit length of the stream, or a diapycnal velocity of $2 \times 10^{-5} \mathrm{~m} \mathrm{~s}^{-1}$ over the $80-\mathrm{km}$ width of the stream. In addition, there is two-way diapycnal mass exchange at approximately the same rate. The rate of inflow from the surface layers of the Sargasso Sea is about $12 \times 10^{6} \mathrm{~m}^{3} \mathrm{~s}^{-1}$, from the thermocline layers $15 \times 10^{6} \mathrm{~m}^{3} \mathrm{~s}^{-1}$.
\end{abstract}

\section{INTRODUCTION}

In a seminal paper, Rossby [1936] discussed the continuity of properties on isopycnal surfaces under the Gulf Stream between the Sargasso Sea and the continental margin. He inferred cross-stream advection along these surfaces and attempted to account for it theoretically. The layers involved were primarily those of the upper thermocline, known to be rich in nutrients [Redfield, 1936]. Although the important idea of analyzing circulation along isopycnal surfaces was soon taken up and applied to the equatorial North Atlantic by Montgomery [1938], western boundary current behavior was not examined again in this manner for a long time.

The concept of a western boundary current originates from ocean circulation models of Stommel [1948] and Munk [1950], according to which a dynamically active deep surface layer is driven by the wind, causing inflow from a Sverdrup interior into a western boundary current, and equal recirculation. If one includes the upper thermocline in the active layer, inflow into the boundary current, and recirculation, is to be expected also in this layer. A different recent idea [Luyten et al., 1983] is that the thermocline circulation originates from the convergence of Ekman transport at the outcropping of the isopycnal surfaces. From there the subducted water mass makes its way again to the western boundary current. It is not clear how this circulation loop is to be closed. Riley [1951] had a conceptual model similar to that of Luyten et al. in mind in examining the behavior of nutrients in the upper thermocline, and he also ended with the nutrients going into the western boundary current. However, a tracer analysis of the North Atlantic thermocline layers by Sarmiento [1983] showed gross discrepancies between Ekman convergence at subduction and what actually flows along upper thermocline layers. In the stratum carrying most of the nutrients (between $\sigma_{t}=26.7$ and 27.3)

Copyright 1991 by the American Geophysical Union.

Paper number $90 \mathrm{JC} 02535$.

$0148-0227 / 91 / 90 \mathrm{JC}-02535 \$ 05.00$
Sarmiento found westward drift of $11 \times 10^{6} \mathrm{~m}^{3} \mathrm{~s}^{-1}$, versus Ekman convergence of $0 \pm 1 \times 10^{6} \mathrm{~m}^{3} \mathrm{~s}^{-1}$.

On account of the importance of nutrient transport to the global biogeochemical cycle, it is clearly desirable to establish from observation just what the mass balance of the nutrient bearing stratum is, and how large a nutrient transport the western boundary current actually carries. Brewer and Dyrssen [1987] obtained first-order estimates for the nitrate and phosphate transport across the Florida Straits and suggested that the Gulf Stream is a principal source of nutrients for the North Atlantic. Here we trace this transport further and show that it increases greatly as the stream flows along the continental margin of North America.

In addition to estimating total nutrient transport, we also examine the questions of how the transport of water mass and nutrients is distributed over the different isopycnal layers, what the downstream increase of the transport implies for the circulation of the nutrient-bearing stratum in the ocean interior, and what the changing profile of nutrient transport reveals about processes within the boundary current itself. Specifically, we examine what support there is in the data for the recently proposed concept of "western boundary upwelling" [Csanady, 1989].

\section{The Data Used}

The tracks of the Gulf Stream-North Atlantic Current hydrographic sections used in our study are shown in Figure 1. They will be identified by the latitude or longitude approximately followed during the cruise: $24^{\circ} \mathrm{N}, 36^{\circ} \mathrm{N}, 64^{\circ} \mathrm{W}$, $53^{\circ} \mathrm{W}$, and $35^{\circ} \mathrm{W}$. The dates of the sections were September 5, 1981, June 12-14, 1981, April 23-28, 1985, May 14-17, 1983 , and July 28 to August 9, 1983, respectively.

All sections were taken in late spring to summer, and two consecutive section pairs $\left(24^{\circ} \mathrm{N}-36^{\circ} \mathrm{N}\right.$ and $\left.53^{\circ} \mathrm{W}-35^{\circ} \mathrm{W}\right)$ were taken in the same year, with a time lapse of only about two and a half months.

The data were kindly made available to us in processed and verified form by M. McCartney of Woods Hole Ocean- 


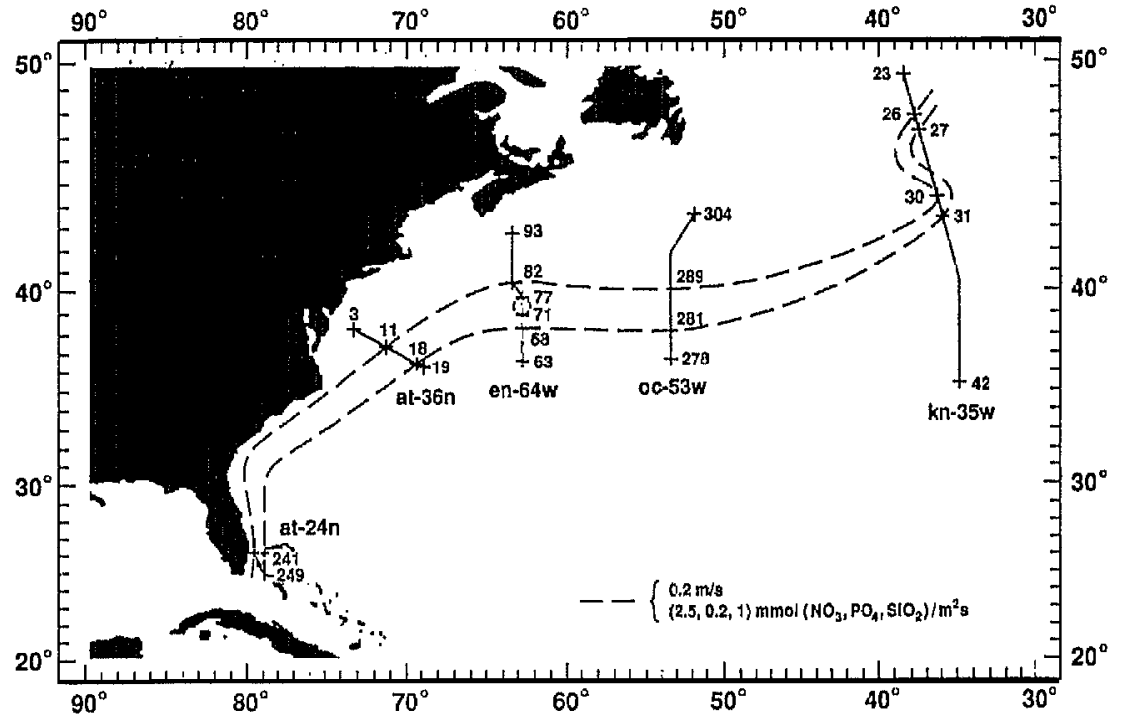

Fig. 1. Hydrographic and nutrient sections employed in this study. The dashed lines indicate the approximate contours for the nutrient stream as defined by the specified nutrient flux density values.

ographic Institute. They included readings of temperature, salinity, nitrate, phosphate, and silicate. From the salinity and temperature data, we have calculated the $\sigma_{t}$ field and geostrophic velocities referred to $2000 \mathrm{~m}$. in all sections except $24^{\circ} \mathrm{N}$. Below this depth the isopycnals were flat enough to guarantee that the relative error in the velocities and transports in the important isopycnal layers is small. In section $24^{\circ} \mathrm{N}$, we used the mean summer velocity field of Niiler and Richardson [1973] for a cross section located about half a degree south of section $24^{\circ} \mathrm{N}$. This is made necessary by the importance of barotropic flow in the Florida Straits.

Flux density $F_{n}$ or transport per unit area, defined as the product of concentration $c$ and velocity normal to the section $i$, was then calculated for the three nutrients named, in all

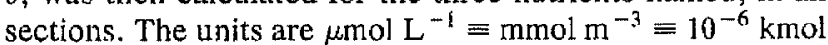
$\mathrm{m}^{-3}$ for nutrient concentration, mmol m $\mathrm{m}^{-2} \mathrm{~s}^{-1} \equiv 10^{-6} \mathrm{kmol}$ $\mathrm{m}^{-2} \mathrm{~s}^{-1}$ for nutrient flux density. Transports given below have units of $\mathrm{kmol} \mathrm{s}^{-1}$.

\section{The Nutrient Stream}

Figure 2 shows the $\sigma_{t}$ and nitrate concentration distributions in section $36^{\circ} \mathrm{N}$, just after the Gulf Stream separates from the continental margin, Figure 3 the calculated velocity and nitrate flux contours. The flux contours define a nutrient stream with a core at about 500-m depth, below and slightly offshore of the high-velocity core of the Gulf Stream. Other nutrients behave similarly to nitrate; see Figure 4 for phosphate and silicate flux contours. Total nutrient transports (flux density integrated over the cross section) are in this section: $863 \mathrm{kmol} \mathrm{s}^{-1}$ for $\mathrm{NO}_{3}, 55 \mathrm{kmol} \mathrm{s}^{-1}$ for $\mathrm{PO}_{4}$, and 508 $\mathrm{kmol} \mathrm{s}^{-1}$ for $\mathrm{SiO}_{2}$.

The continuity of properties along isopycnal surfaces is evident in Figure 2, and in similar sections of other nutrients, not shown. There is one qualification, however, illustrated in Figure 5: nitrate concentration contours in a $\sigma_{t}$-distance map show significant departures from the general horizontal trend at the location of the nutrient stream. Up to $\sigma_{t}=26.8$, i.e., in the lower and mid-thermocline layers, the nitrate concentration is seen to be almost a function of density alone. In lighter layers the concentration shows a maximum at stations 15 and 16 , just seaward of the high-velocity core of the
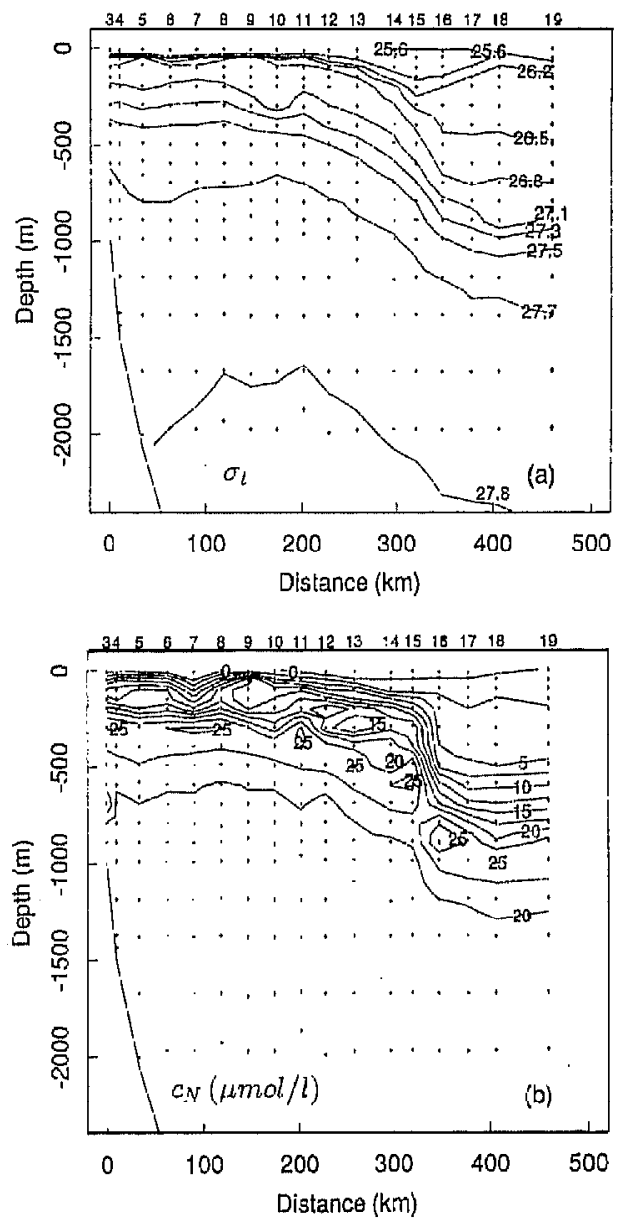

Fig. 2. (a) The $\sigma_{t}$ and (b) nitrate concentration distributions in section $36^{\circ} \mathrm{N}$. 

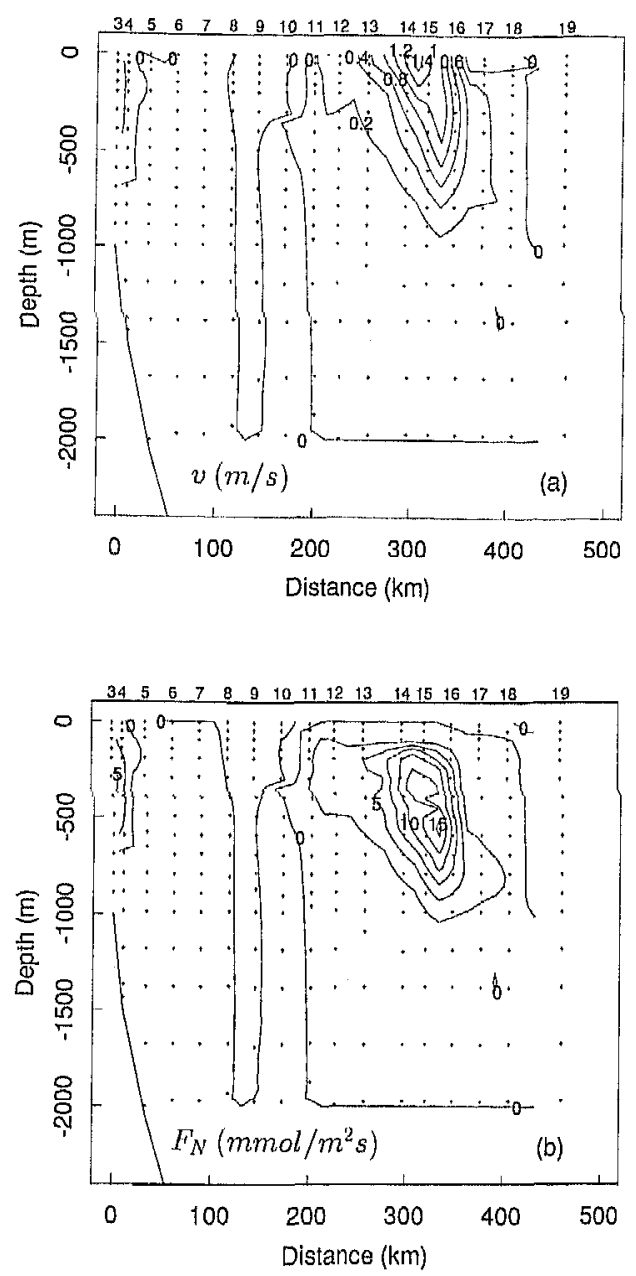

Fig. 3. (a) Velocity and (b) nitrate flux density distributions in section $36^{\circ} \mathrm{N}$.

Gulf Stream. This suggests mixing between the upper thermocline and surface waters, a transfer of nutrients from the nutrient-rich thermocline waters into the nutrient-depleted surface layers. It is important to note that a considerable number of data points show the nutrient maximum in the light layers of the Gulf Stream. However, variations shoreward from this maximum (e.g., near $x=150 \mathrm{~km}$ ) are mostly artifacts of the contouring scheme and should be ignored.

The nutrient stream is identifiable in the other four sections (see Figure 6 for the nitrate flux distributions), although downstream of $36^{\circ} \mathrm{N}$ it has several branches, and at $35^{\circ} \mathrm{W}$ also reverse transport of significant magnitude. Flux intensity is greatest in the Florida Straits and declines monotonically downstream. The total nutrient transport peaks at the $36^{\circ} \mathrm{N}$ section (see Figure 7).

The layers of the Sargasso Sea thermocline between the 26.8 and $27.7 \sigma_{t}$ isopycnal surfaces contain a rich lode of nutrients and may legitimately be called the nutrient bearing stratum of the North Atlantic. Various properties of this stratum were discussed by Riley [1951]. The nutrient stream, or band of high nutrient flux associated with the Gulf Stream system, flows along the western and northern edge of the nutrient bearing stratum. Figure 1 indicates the position of the nutrient stream, estimated from the five sections used here. The contours of the nutrient stream in the figure correspond to flanking nutrient flux density values of (2.5,
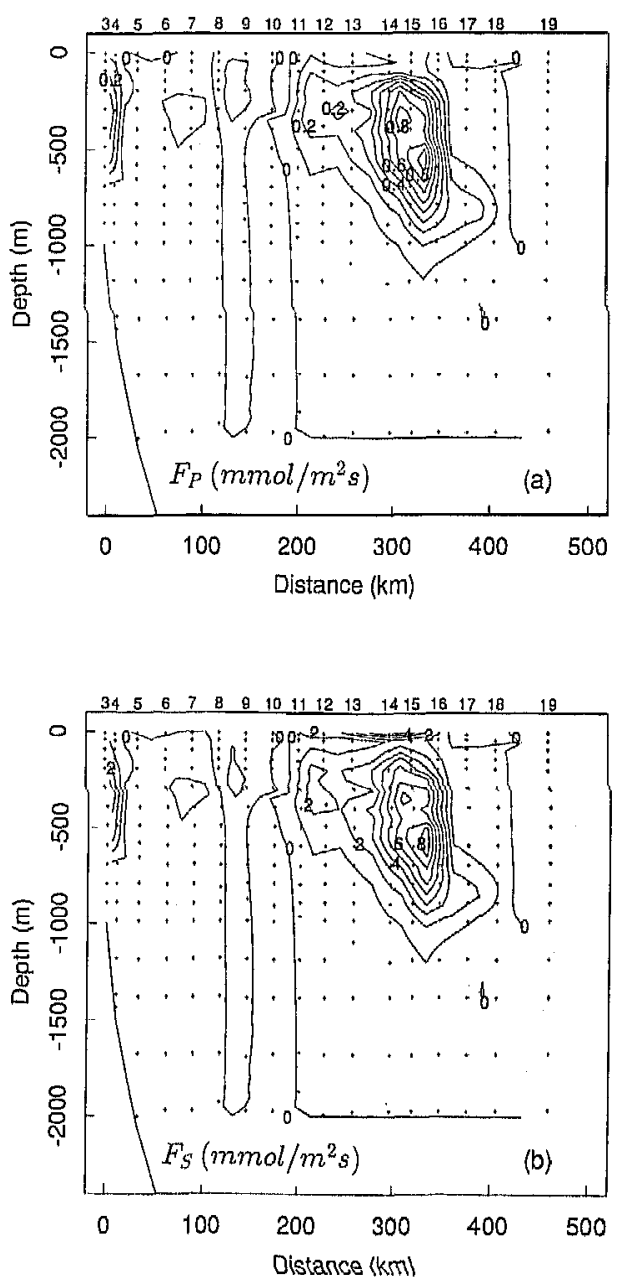

Fig. 4. (a) Phosphate and (b) silicate fux density distributions in section $36^{\circ} \mathrm{N}$.

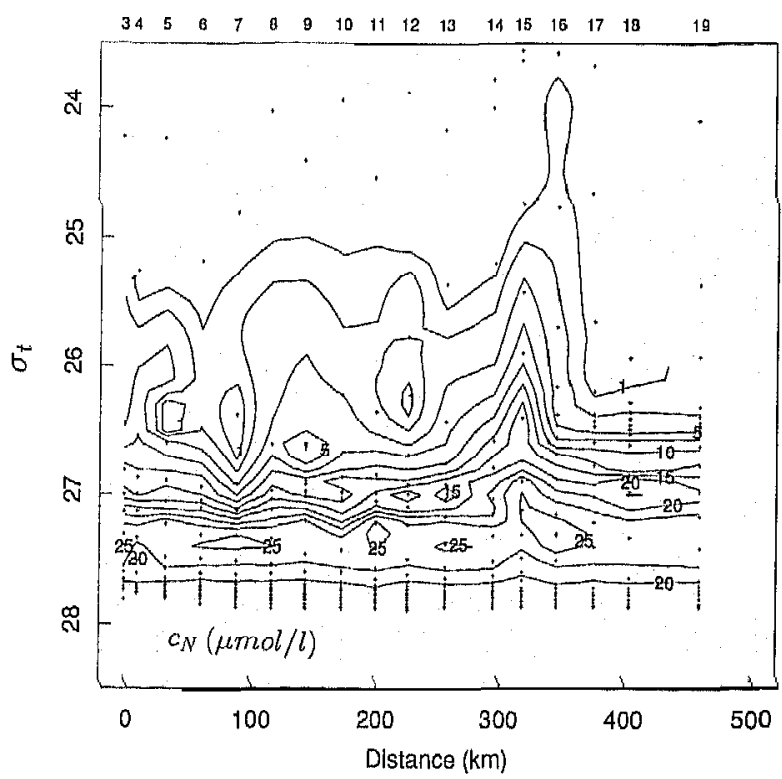

Fig. 5. Nitrate concentration in section $36^{\circ} \mathrm{N}$ as a function of $\sigma_{t}$ and cross-stream distance. 

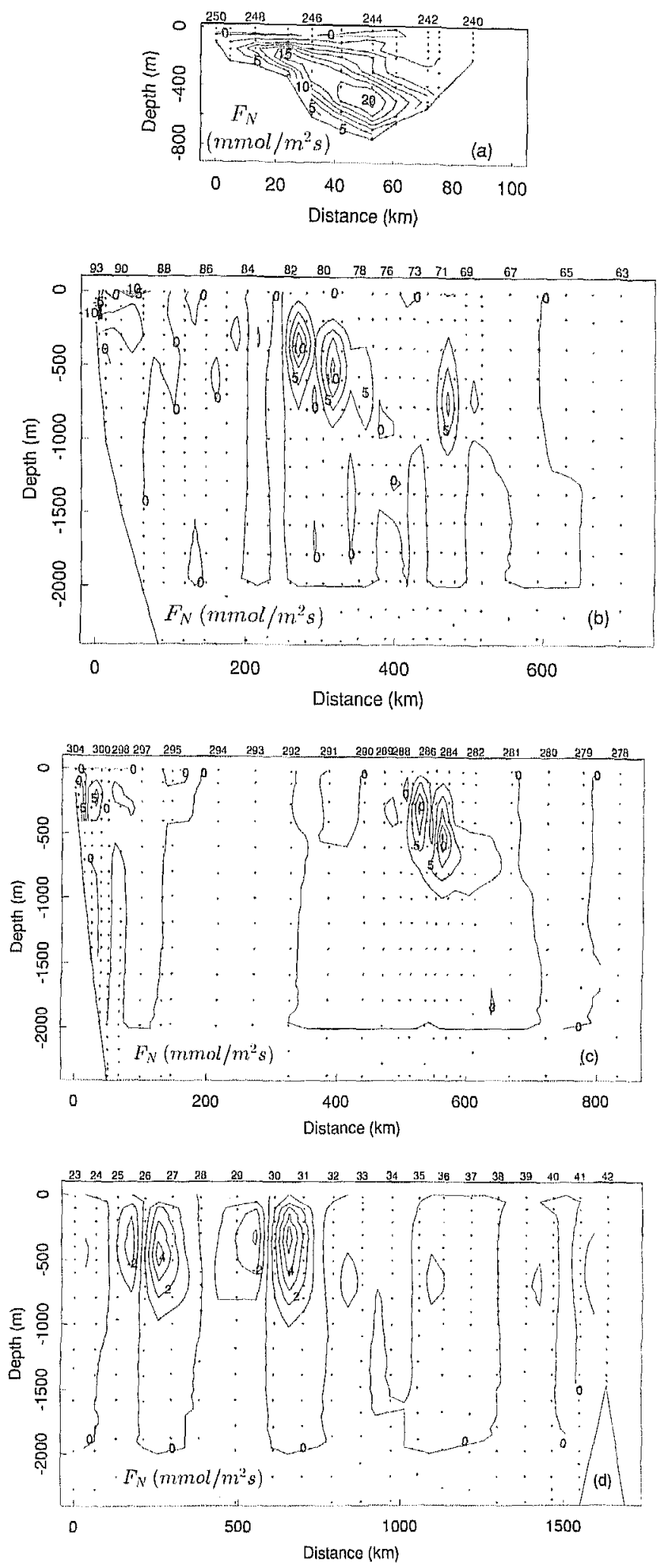

Fig. 6. Nitrate flux density distributions for sections (a) $24^{\circ} \mathrm{N}$, (b) $64^{\circ} \mathrm{W},(c) 53^{\circ} \mathrm{W}$, and $(d) 35^{\circ} \mathrm{W}$. Note that the scales in the $x$ direction are unequal, in a ratio $4: 1: 1: 0.5$. Also note the change in the contour interval for section $35^{\circ} \mathrm{W}$.

$0.2,1) \mathrm{mmol}$ of $\left(\mathrm{NO}_{3}, \mathrm{PO}_{4}, \mathrm{SiO}_{2}\right) \mathrm{m}^{-2} \mathrm{~s}^{-1}$, which roughly coincide with velocity contours of $0.2 \mathrm{~m} \mathrm{~s}^{-1}$. Although it may be conjectured from the nutrient and water mass transport data in Figure 7 that much of the nutrient transport recirculates, a large fraction of it undoubtedly reaches the subpolar gyre.

\section{Water Mass and Nutrient TRansports IN ISOPYCNAL LAYERS}

In addition to the total transports, from the geostrophic velocities and the nutrient flux densities, we have also calculated the transport of water mass and of nutrients in a succession of overlying layers, between the sea surface and the $\sigma_{t}=25.6$ isopycnal surface, and then between pairs of the isopycnals, $\sigma_{t}=25.6,26.2,26.5,26.8,27.1,27.3,27.5$, 27.7 , and 27.8 . The isopycnal $\sigma_{t}=27.8$ approximately coincides with the $2000-\mathrm{m}$ assumed level of no motion. The isopycnals chosen divide the cross section of the Gulf Stream into strips of roughly equal depth. The top three strips are in what Worthington [1976] called warm water, the next two upper thermocline water, the two below that mid-thermocline water, and the last two lower thermocline water. Down to the mid-thermocline, the layers considered by Sarmiento et al. [1982] were nearly the same as ours, although their choice was based on equal surface outcropping areas in winter.

Between an isopycnal layer at depth $z_{i}(x)$ and another at $z_{i+1}(x)$, the water mass and nutrient transports were determined from

$$
\begin{gathered}
V=\int_{0}^{L} d x \int_{z_{i}}^{z i+1} v d z \\
T_{n}=\int_{0}^{L} d x \int_{z_{i}}^{z i+1} c v^{\prime} d z
\end{gathered}
$$

where $x=0$ and $x=L$ were chosen so as to include all significant baroclinic transport by the Gulf Stream. The concentration in each layer was taken to be the arithmetic average of the observations between the same limits on $x$ and $z$ as $V$ and $T_{n}$. This average $c_{n}$ differed little from $T_{n} / V$. Units used are sverdrups $\left(10^{6} \mathrm{~m}^{3} \mathrm{~s}^{-1}\right)$ and $\mathrm{kmol} \mathrm{s}^{-1}$.

Table 1 contains $V$ and $T_{n}$ for nitrate, phosphate, and silicate in all the isopycnal layers mentioned, for the two sections $24^{\circ} \mathrm{N}$ and $36^{\circ} \mathrm{N}$. As is well known, the baroclinic water mass transport of the Gulf Stream roughly doubles between these two sections. Nutrient transports, however, are seen to treble. For the discussion here the distribution of the increase over the different isopycnal layers is of prime interest. The increases are generally of the same order as the "upstream" transport at section $24^{\circ} \mathrm{N}$, and therefore dwarf any errors in the transport estimates.

Expressed as a fraction of the upstream water transport, the increases in $V$ in the various layers range from zero to $200 \%$, with a pronounced broad maximum between the $\sigma_{t}=$ 26.5 and 27.3 isopycnal surfaces (excluding the bottom two layers, which are vestigial upstream). The increases in mass transport will be attributed to along-isopycnal inflow from the Sargasso Sea, with qualifications to be developed later. As may be seen in Figure 8, the layer to layer data scatter a bit but show that most of the mass transport increase occurs in the upper thermocline layers. Because these are the layers constituting the nutrient bearing stratum, the much greater than proportionate increase of nutrient transport is at once 


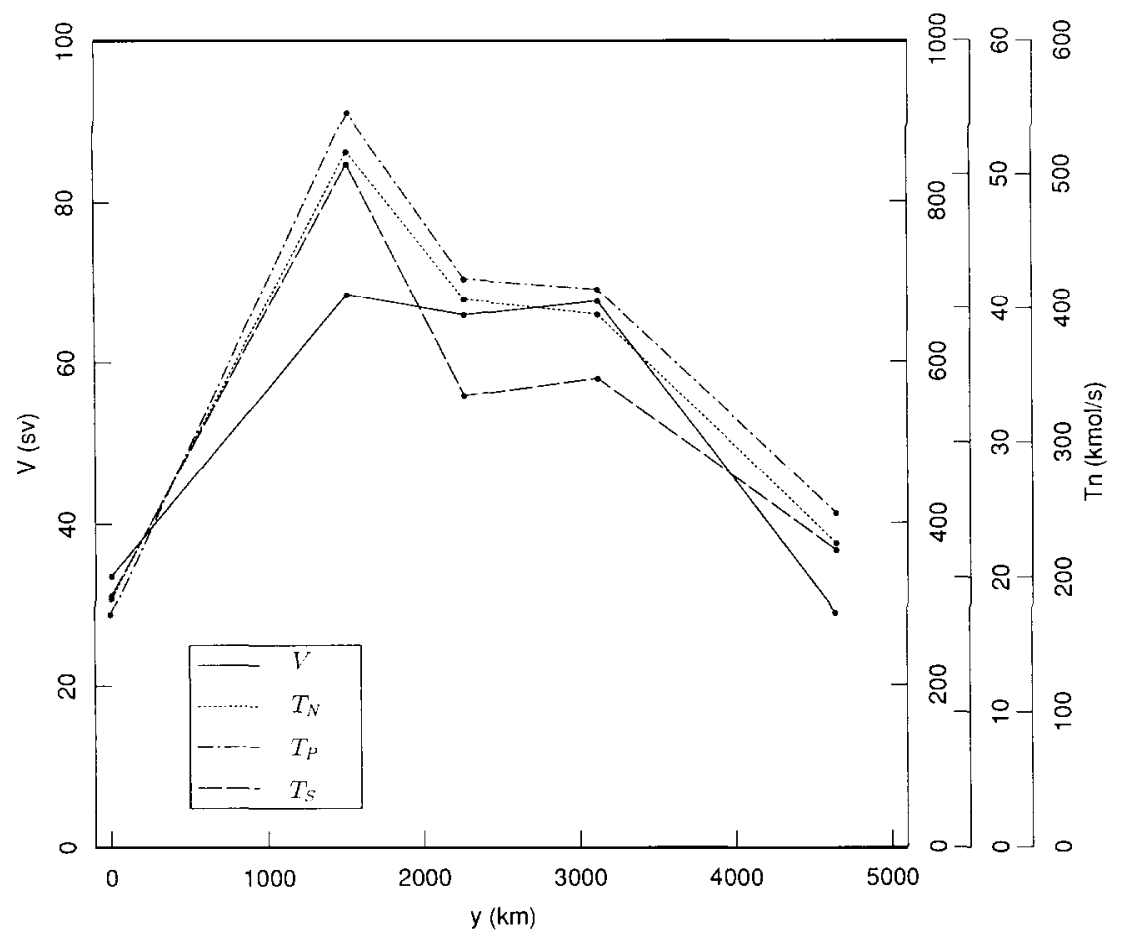

Fig. 7. Variation of total water mass and nutrient transports with along-stream distance. The three scales in the right margin correspond to nitrate, phosphate, and silicate transport, respectively.

explained by the predominance of the inflow from that stratum.

Although this explanation is borne out in a general way by an examination of the nutrient transport changes, there are some important discrepancies. Let an "advective" concentration be defined by

$$
c_{a}=\frac{T_{n 2}-T_{n 1}}{V_{2}-V_{1}}
$$

where the numeric subscripts refer to the upstream and downstream sections. If inflow took place strictly along isopycnals, the advective concentration would equal some weighted mean of the concentrations $c_{n 1}$ and $c_{n 2}$ (which only differ by about $10 \%$, so that $c_{n 2}$ is a reasonable approximation to the concentration in the inflow). As long as the increases in both mass transport and nutrient transport in a given layer are of the order of the upstream transports, any major differences between $c_{a}$ and $c_{n 2}$ are significant and require an explanation. An advective concentration much larger than layer concentration implies excess nutrient supply, the opposite difference a deficiency.

Excluding the uppermost layer and the two bottom layers from consideration (because the $\Delta V / V$ ratio is too small or too large for this argument), significant excess nutrient supply is found in the layers above the $\sigma_{t}=26.8$ isopycnal, deficiency below. Combining all the layers above this isopycnal into a single "surface" stratum, and all those down to $\sigma_{t}=27.5$ into a "thermocline" stratum, one finds a weighted average $c_{a}$ about twice $c_{n 2}$ in the surface stratum, a $15 \%$ deficiency in the thermocline stratum. Expressed in terms of total nitrate transports, the increase in the surface stratum is $160 \mathrm{kmol} \mathrm{s}^{-1}$, only half of which is explained by the

TABLE 1. Water Mass (Sverdrups) and Nutrient Transports $\left(\mathrm{kmol} \mathrm{s}^{-1}\right)$ and Concentrations $\left(\mu \mathrm{mol} \mathrm{L}{ }^{-1}\right)$ in Sections $24^{\circ} \mathrm{N}$ and $36^{\circ} \mathrm{N}$

\begin{tabular}{|c|c|c|c|c|c|c|c|c|c|c|c|c|c|c|}
\hline \multirow[b]{2}{*}{ Layer } & \multirow[b]{2}{*}{$V_{1}$} & \multirow[b]{2}{*}{$V_{2}$} & \multicolumn{4}{|c|}{$\mathrm{NO}_{3}$} & \multicolumn{4}{|c|}{$\mathrm{PO}_{4}$} & \multicolumn{4}{|c|}{$\mathrm{SiO}_{2}$} \\
\hline & & & $T_{n 1}$ & $T_{n 2}$ & $c_{a}$ & $c_{n 2}$ & $T_{n 1}$ & $T_{n 2}$ & $c_{a}$ & $c_{n 2}$ & $T_{n 1}$ & $T_{n 2}$ & $c_{a}$ & $c_{n 2}$ \\
\hline$<25.6$ & 12.14 & 12.62 & 12.74 & 16.62 & 8.08 & 1.02 & 0.79 & 1.90 & 2.31 & 0.14 & 19.09 & 27.29 & 17.08 & 2.02 \\
\hline $25.6-26.2$ & 3.26 & 6.63 & 14.33 & 43.71 & 8.72 & 4.32 & 0.71 & 2.57 & 0.55 & 0.26 & 6.68 & 21.03 & 4.26 & 2.21 \\
\hline $26.2-26.5$ & 6.30 & 7.96 & 35.47 & 59.02 & 14.19 & 4.66 & 1.73 & 3.18 & 0.87 & 0.27 & 15.88 & 27.68 & 7.11 & 2.13 \\
\hline $26.5-26.8$ & 4.08 & 12.47 & 52.94 & 154.58 & 12.11 & 10.73 & 2.77 & 9.08 & 0.75 & 0.62 & 22.89 & 73.01 & 5.97 & 4.71 \\
\hline $26.8-27.1$ & 3.81 & 11.69 & 80.10 & 219.27 & 17.66 & 18.18 & 4.55 & 13.71 & 1.16 & 1.14 & 42.25 & 115.57 & 9.30 & 9.39 \\
\hline $27.1-27.3$ & 1.55 & 4.99 & 42.75 & 112.55 & 20.29 & 22.30 & 2.55 & 7.20 & 1.35 & 1.43 & 27.79 & 67.91 & 11.66 & 13.35 \\
\hline $27.3-27.5$ & 2.26 & 3.61 & 64.19 & 86.66 & 16.64 & 24.09 & 3.94 & 5.65 & 1.27 & 1.57 & 48.55 & 56.30 & 5.74 & 15.60 \\
\hline $27.5-27.7$ & 0.11 & 4.19 & 3.38 & 88.71 & 20.92 & 20.96 & 0.20 & 5.91 & 1.40 & 1.40 & 2.84 & 60.11 & 14.04 & 14.17 \\
\hline $27.7-27.8$ & 0.13 & 4.34 & 2.87 & 81.70 & 18.16 & 18.74 & 0.15 & 5.48 & 1.27 & 1.25 & 1.39 & 59.38 & 13.77 & 13.99 \\
\hline All & 33.65 & 68.50 & 308.75 & 862.81 & 15.90 & 16.92 & 17.39 & 54.68 & 1.07 & 1.11 & 187.36 & 508.28 & 9.21 & 11.50 \\
\hline$<26.8$ & 25.78 & 39.69 & 115.47 & 273.93 & 11.39 & 5.83 & 6.00 & 16.73 & 0.77 & 0.35 & 64.54 & 149.01 & 6.07 & 3.01 \\
\hline $26.8-27.5$ & 7.62 & 20.28 & 187.03 & 418.48 & 18.28 & 21.01 & 11.04 & 26.56 & 1.23 & 1.34 & 118.59 & 239.78 & 9.57 & 12.26 \\
\hline $27.5-27.8$ & 0.25 & 8.53 & 6.25 & 170.41 & 19.83 & 19.25 & 0.35 & 11.39 & 1.33 & 1.29 & 4.23 & 119.49 & 13.92 & 14.03 \\
\hline
\end{tabular}




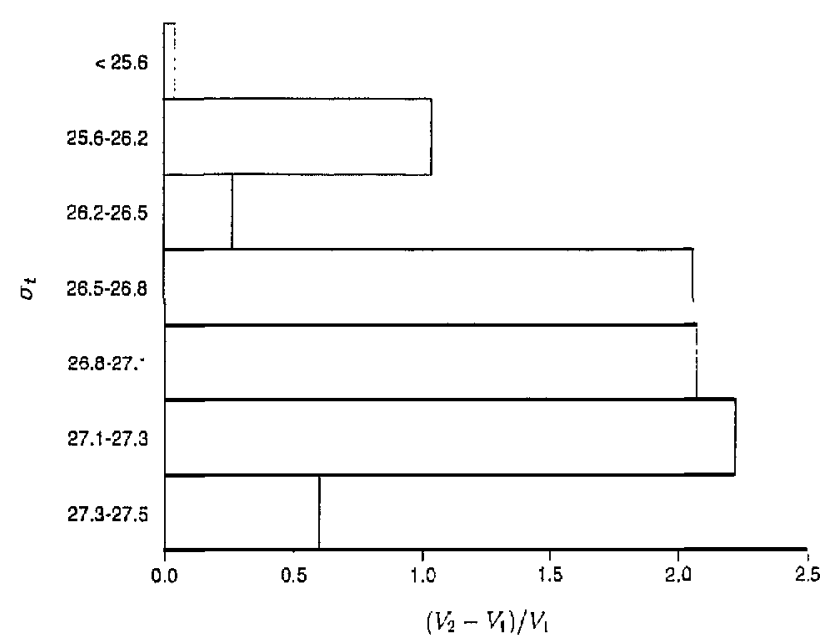

Fig. 8. Relative increase between sections $24^{\circ} \mathrm{N}$ and $36^{\circ} \mathrm{N}$ of water mass transport in isopyenal layers.

isopycnal inflow. In the thermocline, the increase is 230 $\mathrm{kmol} \mathrm{s}^{-1}$, in place of $265 \mathrm{kmol} \mathrm{s}^{-1}$ if the inflow were isopycnal. Similar differences occur with the other nutrients (see Table 1). As may be expected, the exact amount of the smaller discrepancy in the thermocline scatters more, its average over the three nutrients being $17 \%$.

\section{Mixing ANd Entrainment}

The "excess" nutrient transport observed in the surface stratum, and the concentration anomalies over the nutrient stream (Figure 5) suggest mixing (two-way exchange) and possibly entrainment (one-way mass transfer) of thermocline waters into the surface stratum. A two-box model of the Gulf Stream between the two sections $24^{\circ} \mathrm{N}$ and $36^{\circ} \mathrm{N}$ (Figure 9) can be used to estimate the rates of these diapycnal transfer processes. Given the large nutrient transport increases, nutrient utilization is legitimately ignored in the mass balances (see discussion below). The large water mass transports, and the large increase in these transports, makes it realistic to suppose steady state (ignore "storage" of water between sections) and to neglect any exchange with the continental margin. The water mass and nutrient balances for the surface and thermocline strata are then

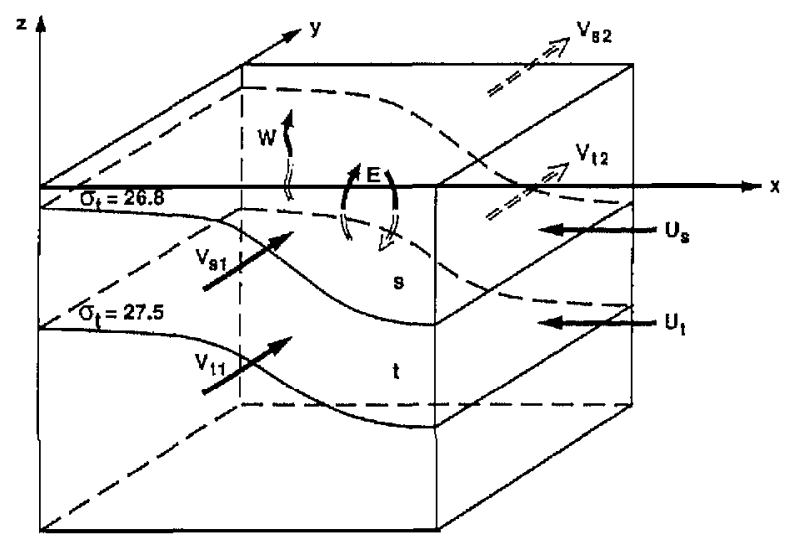

Fig. 9. Schenatic representation of the main elements for the two-box model of the Gulf Stream between sections $24^{\circ} \mathrm{N}$ and $36^{\circ} \mathrm{N}$.

$$
\begin{gathered}
\Delta V_{s}=U_{s}+W \\
\Delta T_{s}=c_{s} U_{s}+W c_{t}+E\left(c_{t}-c_{s}\right) \\
\Delta V_{t}=U_{t}-W \\
\Delta T_{t}=c_{t} U_{t}-W c_{t}-E\left(c_{t}-c_{s}\right)
\end{gathered}
$$

where the $\Delta V$ are increases in water mass transport, the $\Delta T$ increases in nutrient transport, $U_{s}$ and $U_{t}$ are infows from the surface and thermacline strata, $W$ is the entrainment rate, and $E$ is the exchange rate. These equations are readily solved for the four unknowns $U_{s}, U_{t}, W$, and $E$.

The neglect of nutrient utilization is readily justified by empirical data obtained in the South Atlantic Bight. Yoder et al. [1983] quote new production rates at the edge of the continental shelf, implying nitrate utilization at the rate of $2.2 \times 10^{-6} \mathrm{kmol} \mathrm{m}^{-2} \mathrm{~d}^{-1}$, similar to rates used by Walsh et al. [1988], 3-5 $\times 10^{-6} \mathrm{kmol} \mathrm{m}^{-2} \mathrm{~d}^{-1}$, in a numerical model of production in the Mid-Atlantic Bight. Supposing a utilization rate of $3 \times 10^{-6} \mathrm{kmol} \mathrm{m}^{-2} \mathrm{~d}^{-1}$ over a $100 \mathrm{~km}$-wide strip between sections $24^{\circ} \mathrm{N}$ and $36^{\circ} \mathrm{N}(1500 \mathrm{~km}$ apart) gives a nitrate transport loss of $5 \mathrm{kmol} \mathrm{s}^{-1}$, or $3 \%$ of the calculated increase in transport in the surface layer, which is certainly at the noise level. To utilize hundreds of $\mathrm{kmol} \mathrm{s}^{-1}$ at the empirical utilization rates would take an area the size of a subtropical gyre. Therefore utilization is important for the balance of nutrients between whole transoceanic sections (as discussed by Brewer and Dyrssen for such a section at $24^{\circ} \mathrm{N}$ ), but not between sections of an intense nutrient stream.

Equations (3) may be applied separately to the nitrate, phosphate, and silicate transports, yielding three sets of estimates for inflow and mixing rates. These are shown in Table 2. While the estimates scatter somewhat (especially for the entrainment rate $W$ ), they all show similar inflow rates into the surface and thermocline strata, upward entrainment, and significant two-way exchange. Realistic mean rates, with error bars, are as follows (all in sverdrups):

$$
\begin{aligned}
& U_{s}=12 \pm 1.5 \\
& U_{t}=15 \pm 1.9 \\
& W=2.4 \pm 1.9 \\
& E=2.4 \pm 1.2
\end{aligned}
$$

The along-stream distance between the two sections is about $1500 \mathrm{~km}$, so that the entrainment and exchange rates per unit length of the stream are $1.6 \mathrm{~m}^{2} \mathrm{~s}^{-1}$, with fairly wide error bars. Distributed over the $80 \mathrm{~km}$ width of the stream the entrainment and mass transfer coefficients are both about 2 $\times 10^{-5} \mathrm{~m} \mathrm{~s}^{-1}$. An upwelling velocity of similar magnitude characterizes equatorial upwelling [Wyrtki, 1981].

TABLE 2. Estimates for Inflow and Mixing Water Mass Transports (Sverdrups) Between Sections $24^{\circ} \mathrm{N}$ and $36^{\circ} \mathrm{N}$ Obtained From the Two-Box Model

\begin{tabular}{ccccc}
\hline Nutrient & $U_{s}$ & $U_{1}$ & $W$ & $E$ \\
\hline $\mathrm{NO}_{3}$ & 11.53 & 15.04 & 2.38 & 2.17 \\
$\mathrm{PO}_{4}$ & 9.62 & 16.95 & 4.29 & 1.19 \\
$\mathrm{SiO}_{2}$ & 13.44 & 13.12 & 0.47 & 3.53 \\
\hline
\end{tabular}


TABLE 3. Water Mass Transports (Sverdrups) and Nitrate Transports $\left(\mathrm{kmol} \mathrm{s}^{-1}\right)$ in the Surface $s\left(\sigma_{t}<26.8\right)$, Thermocline $t\left(26.8<\sigma_{t}<27.5\right)$, and Deep Strata $d\left(27.5<\sigma_{t}<27.8\right)$ of + Five Sections

\begin{tabular}{lccccc}
\hline & \multicolumn{5}{c}{ Section } \\
\cline { 2 - 6 } & $24^{\circ} \mathrm{N}$ & $36^{\circ} \mathrm{N}$ & $64^{\circ} \mathrm{W}$ & $53^{\circ} \mathrm{W}$ & $35^{\circ} \mathrm{W}$ \\
\hline$V_{s}$ & 25.78 & 39.69 & 40.87 & 43.86 & 4.48 \\
$V_{t}$ & 7.62 & 20.28 & 18.54 & 17.57 & 21.05 \\
$V_{d}$ & 0.25 & 8.53 & 6.44 & 6.18 & 3.49 \\
$T_{N s}$ & 115.5 & 273.9 & 187.8 & 220.8 & 17.5 \\
$T_{N t}$ & 187.0 & 418.5 & 362.3 & 314.7 & 292.6 \\
$T_{N d}$ & 6.3 & 170.4 & 128.0 & 123.5 & 65.4 \\
\hline
\end{tabular}

Water mass and nitrate transports in different strata of all five sections are shown in Table 3 (with $\sigma_{t}<25.6$ included in the surface stratum). Transports of other nutrients behave similarly to nitrate. Between sections $36^{\circ} \mathrm{N}-64^{\circ} \mathrm{W}$ and $64^{\circ} \mathrm{W}-$ $53^{\circ} \mathrm{W}$ there is little inflow or outflow; from $53^{\circ} \mathrm{W}$ to $35^{\circ} \mathrm{W}$ there is large outflow from the surface stratum and inflow into the thermocline. Application of the above box model to these section pairs cannot be justified because the $\Delta V / V$ requirement is not met, and indeed it leads to erratic results.

\section{CONCLUSION}

The results here reinforce and flesh out the idea of Brewer and Dyrssen [1987] that the Gulf Stream is a major source of nutrients for the North Atlantic. A nutrient stream flows under the Gulf Stream and the North Atlantic Current, with its core at only 500-m depth and carries a very large supply of nutrients northeastward. Only about a third of the supply comes through the Florida Straits, the rest from the Sargasso Sea thermocline, arriving between the straits and the MidAtlantic Bight. The water transport from the subtropical gyre into the western boundary current is dominated by inflow from the thermocline. Because the upper thermocline is the principal nutrient-bearing stratum, the inflow from there into the nutrient stream is responsible for the large increase in nutrient transport.

The proximity of the nutrient stream to the surface already suggests the likelihood of nutrients reaching the surface layers. The mass balance of individual isopycnal layers shows clear evidence not only for thermocline-surface mass exchange, but also net diapycnal mass transfer. The intensity of this "western boundary upwelling" is high enough to rival the most intense upwelling observable in the ocean: equatorial upwelling.

The ideas underlying the concept of western boundary upwelling are that energy dissipation in oceanic gyres is concentrated in western boundary currents, and that the first phase of dissipation is the release of potential energy to the "primary" eddies and meanders growing on the current. This first phase involves the upward movement of relatively light fluid along isopycnals, across the direction of the mean current, in accordance with the baroclinic instability mechanism. The eddy energy is eventually transmitted to the environment and dissipated (for example, through the radiation of topographic waves). The dissipation makes the rise of the light fluid permanent.
Our estimate for entrainment plus exchange from the thermocline to the surface layers, $3.2 \mathrm{~m}^{2} \mathrm{~s}^{-1}$, is similar to the estimate of western boundary upwelling, about $4 \mathrm{~m}^{2} \mathrm{~s}^{-1}$, obtained by Csanady and Hamilton [1988]. The source for this upward transfer is undoubtedly the along-isopycnal inflow from the upper thermocline, at the rate of some $10 \mathrm{~m}^{2}$ $\mathrm{s}^{-1}$. Although upward entrainment is not the same as upward advection along isopycnal surfaces, the two are undoubedly connected: upward entrainment takes place where an isopycnal surface approaches the sea surface and is supplied from below by isopycnal advection. Upward entrainment is presumably due to episodic high shear between isopycnal layers, occurring in meanders.

Acknowledgments. We would like to thank Mike McCartney of WHOI for graciously providing the processed hydrographic data. The work described above has been supported by the Department of Energy under a grant entitled "The role of continental margin processes in the nutrient bearing stratum of the North Atlantic."

\section{REFERENCES}

Brewer, P. G., and D. Dyrssen, Ocean chemical fluxes across $25^{\circ} \mathrm{N}$ in the Atlantic Ocean, paper presented at the International Global Ocean Flux Study Meeting, Paris, Feb.17-20, 1987.

Csanady, G. T., Energy dissipation and upwelling in a western boundary current, J. Phys. Oceanogr., 19, 462-473, 1989.

Csanady, G. T., and P. Hamilton, Circulation of slopewater, Continental Shelf Res., 8, 565-624, 1988.

Luyten. J., J. Pedlosky, and H. Stommel, The ventilated thermocline, J. Phys. Oceanogr., 13, 292-309, 1983.

Montgomery, R. B., Circulation in upper layers of southern North Atlantic deduced with use of isentropic analysis, Pap. Phys. Oceanogr. Meteorol., 6, 55 pp., 1938.

Munk, W. H., On the wind-driven ocean circulation, J. Meteorol, 7, 79-93, 1950.

Niiler, P. N., and W. S. Richardson, Seasonal variability of the Florida current, J. Mar. Res., 31, 144-167, 1973.

Redfield, A. C., An ecological aspect of the Gulf Stream, Nature, $138,1013,1936$.

Riley, G. A., Oxygen, phosphate and nitrate in the Atlantic Ocean, Bull. Bingham Oceanogr. Collect., 13, 1-125, 1951.

Rossby, C. G., Dynamics of steady ocean currents in the light of experimental fluid mechanics, Pap. Phys. Oceanogr. Meteorol., $5,1-43,1936$.

Sarmiento, J. L., A tritium box model of the North Atlantic thermocline, J. Phys. Oceanogr., 13, 1269-1274, 1983.

Sarmiento, J. L., C. G. H. Rooth, and W. Roether, The North Atlantic tritium distribution in 1972, J. Geophys. Res., 87, 80478056, 1982.

Stommel, H., The westward intensification of wind-driven ocean currents, Eos Trans. $A G U, 29,202-206,1948$.

Walsh, J. J., D. A. Dieterle, and M. B. Meyers, A simulation analysis of the fate of phytoplankton within the Mid-Atlantic Bight, Continental Shelf Res., 8, 757-787, 1988.

Worthington, L. V., On the North Atlantic circulation, Johns Hopkins Oceanogr. Stud., 6, 110 pp., 1976.

Wyrtki, K., An estimate of equatorial upwelling in the Pacific, $J$. Phys. Oceanogr., 11, 1205-1214, 1981.

Yoder, J. A., L. A. Atkinson, S. S. Bishop, E. E. Hofmann, and T. N. Lee, Effect of upwelling on phytoplankton productivity of the outer southeastern United States continental shelf, Continental Shelf Res., I, 385-404, 1983.

G. T. Csanady and J. L. Pelegrí, Department of Oceanography, Old Dominion University, Norfolk, VA 23529.

(Received August 22, 1990; revised October 29, 1990; accepted October 30, 1990.) 